\title{
Why study bycatch? An introduction to the Theme Section on fisheries bycatch
}

\author{
Candan U. Soykan ${ }^{1, *}$, Jeffrey E. Moore ${ }^{2}$, Ramūnas Žydelis ${ }^{2}$, Larry B. Crowder ${ }^{2}$, \\ Carl Safina $^{3}$, Rebecca L. Lewison ${ }^{1}$ \\ ${ }^{1}$ Biology Department, San Diego State University, 5500 Campanile Dr., San Diego, California 92182-4614, USA \\ ${ }^{2}$ Center for Marine Conservation, Nicholas School of the Environment, Duke University Marine Laboratory, \\ 135 Duke Marine Lab Road, Beaufort,North Carolina 28516, USA \\ ${ }^{3}$ Blue Ocean Institute, PO Box 250, East Norwich, New York 11732, USA
}

\begin{abstract}
Several high-profile examples of fisheries bycatch involving marine megafauna (e.g. dolphins in tuna purse-seines, albatrosses in pelagic longlines, sea turtles in shrimp trawls) have drawn attention to the unintentional capture of non-target species during fishing operations, and have resulted in a dramatic increase in bycatch research over the past 2 decades. Although a number of successful mitigation measures have been developed, the scope of the bycatch problem far exceeds our current capacity to deal with it. Specifically, we lack a comprehensive understanding of bycatch rates across species, fisheries, and ocean basins, and, with few exceptions, we lack data on demographic responses to bycatch or the in situ effectiveness of existing mitigation measures. As an introduction to this theme section of Endangered Species Research 'Fisheries bycatch: problems and solutions', we focus on 5 bycatch-related questions that require research attention, building on examples from the current literature and the contributions to this Theme Section. The questions include: (1) Where is bycatch most prevalent? (2) Which species are taken as bycatch? (3) Which fisheries and gear types result in the highest bycatch of marine megafauna? (4) What are the population-level effects on bycatch species? And (5) How can bycatch be reduced? By addressing these questions, we draw attention to several emerging issues: the importance of artisanal fisheries bycatch, the demographic effects of bycatch, and the need for comprehensive, trans-national mitigation efforts. Although science alone cannot address the complex social, economic, and political factors that contribute to the bycatch problem, this review illustrates ways in which research can contribute to effective bycatch solutions.
\end{abstract}

KEY WORDS: Bycatch · Marine megafauna · Marine mammal - Seabird · Sea turtle · Artisanal fishery $\cdot$ Mitigration $\cdot$ Demographic effects

\section{INTRODUCTION}

Over the last 2 decades bycatch, the unintentional capture of non-target species during fishing operations, has become a major issue in global fisheries management and conservation (Kelleher 2005), particularly for long-lived marine megafauna such as sharks, sea turtles, seabirds, and marine mammals (Lewison et al. 2004a). Individual fishers often underestimate the cumulative effect of all fishing activities because bycatch of these species is a relatively rare event and represents a small fraction of the total bycatch biomass. However, given the life history characteristics of most marine megafauna (slow growth, low reproductive rates, high adult survival), relatively low levels of bycatch can have a large effect on population viability (Heppell et al. 2000). Many of these species are threatened (sensu International Union for Conservation of Nature, IUCN), having suffered declines as a result of excessive incidental mortality caused by fisheries (Lewison et al. 2004b, Arnold et al. 2006, JaramilloLegorreta et al. 2007). 
Increased concern over bycatch is reflected by a marked increase in research over the past few decades (Fig. 1). Bycatch research is any form of scientific inquiry that has the potential to contribute to the reduction of incidental mortality caused by fisheries (although we focus this review on marine mammals, seabirds, and sea turtles). This may include research that identifies bycatch vulnerability or susceptibility, direct bycatch reduction through changes in fishing gear or practices, indirect bycatch reduction via improved understanding of the spatio-temporal distribution of bycatch events and species, the relevant behavior of affected species, characteristics of the fisheries that result in bycatch, or the demographic consequences of bycatch.

There has been substantial progress in the development of gear and fishing practices, along with fishing effort reductions and reallocations, that reduce bycatch of sea turtles, seabirds, and marine mammals in different ocean areas and fisheries (Hall \& Mainprize 2005, Werner et al. 2006, Mug et al. 2008). For example, dolphin bycatch in the Pacific tuna purse-seine fishery has been reduced drastically by changes in fishing practices (Hall 1998), while the use of turtle excluder devices has reduced sea turtle bycatch in the

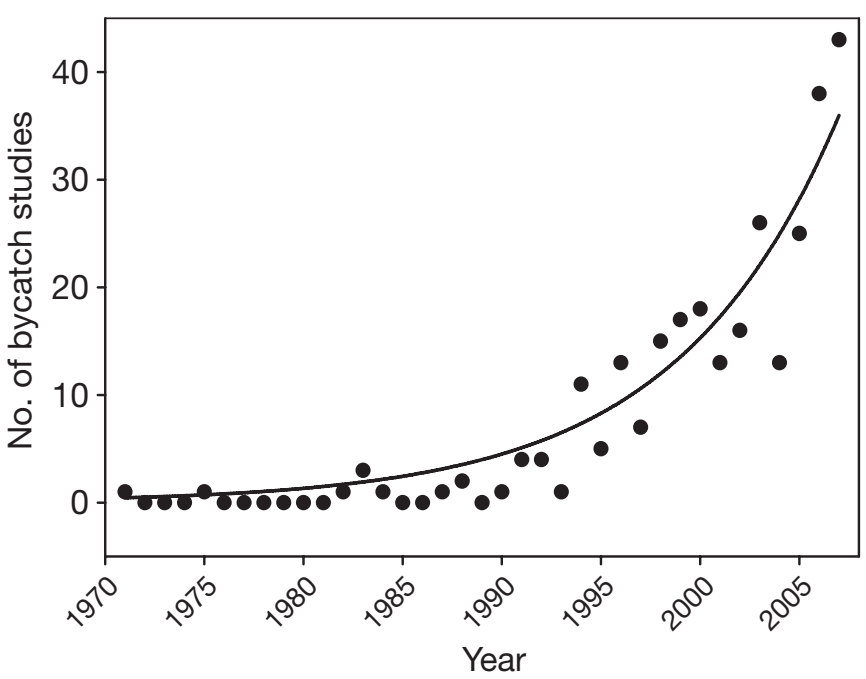

Fig. 1. Number of peer-reviewed publications per year containing any word associated with fisheries bycatch in the title, abstract, or keywords and dealing with marine mammals, seabirds, and/or sea turtles, based on a Web-of-Science (http://wok.mimas.ac.uk) search using the following keywords: bycatch, incidental catch, incidental capture, non-target catch, bykill, inadvertent catch, accidental catch, accidental capture, incidental catch, incidental capture. The following terms: by-kill, incidental take, and by-catch yielded thousands of studies each as a result of imprecise keyword identification and were therefore left out of our search. Thus, our survey likely overlooked some studies and these results should be interpreted as representative, rather than comprehensive
Gulf of Mexico and Australia's northern prawn fishery (Cox et al. 2007). Longline fisheries bycatch of seabirds and sea turtles has been reduced through gear modification (tori lines, weighted lines, circle hooks; Watson et al. 2005, Kerstetter \& Graves 2006, Bull 2007) and changes in fishing practices (no dumping of offal during setting, side setting of lines, night setting; Werner et al. 2006, Bull 2007, Gilman et al. 2007). The use of pingers has reduced bycatch of marine mammals in some areas (Kraus et al. 1997, Barlow \& Cameron 2003). Thus, for many different species and gear types, considerable progress has been made in reducing fisheries bycatch.

Given these examples, a logical question presents itself: Why is more bycatch research needed? Should we not just invest in mitigation to solve bycatch problems? Drawing on the contributions to this Theme Section and the wider bycatch literature we argue that, in spite of years of bycatch study on threatened species, we lack a comprehensive picture of bycatch across species, fisheries, and ocean basins. Moreover, with few exceptions, we lack detail on demographic responses to bycatch, or the in situ effectiveness of existing mitigation measures. These knowledge gaps persist due to the diversity of taxa taken as bycatch, the wide range of environmental conditions in the world's fisheries, differences in fishing gear and practices, the geographic extent of bycatch, political and economic obstacles to the study of bycatch, and challenges associated with studying long-lived marine species.

Bycatch is one of several issues that challenge fisheries sustainability. Others include habitat degradation (Turner et al. 1999), overcapacity (Beddington et al. 2007), lack of infrastructure, management, and oversight (Salas et al. 2007), inappropriate management paradigms (Bundy et al. 2008), lack of stakeholder involvement (Dankel et al. 2008), and a lack of public awareness (Novacek 2008). While scientific inquiry alone cannot solve the bycatch problem (Bundy et al. 2008), this review focuses on those areas where research can contribute to the goal of minimizing bycatch of vulnerable populations and promoting sustainable fishing practices.

\section{ESTABLISHING GLOBAL BYCATCH RESEARCH PRIORITIES}

Continued research is needed to address the following 5 essential questions associated with bycatch.

(1) Where is bycatch of threatened species most prevalent? Although ubiquitous, bycatch of marine megafauna is not uniformly distributed (Lewison et al. in press), nor is the geographic distribution of bycatch research (Fig. 2). Moreover, the distribution of bycatch 


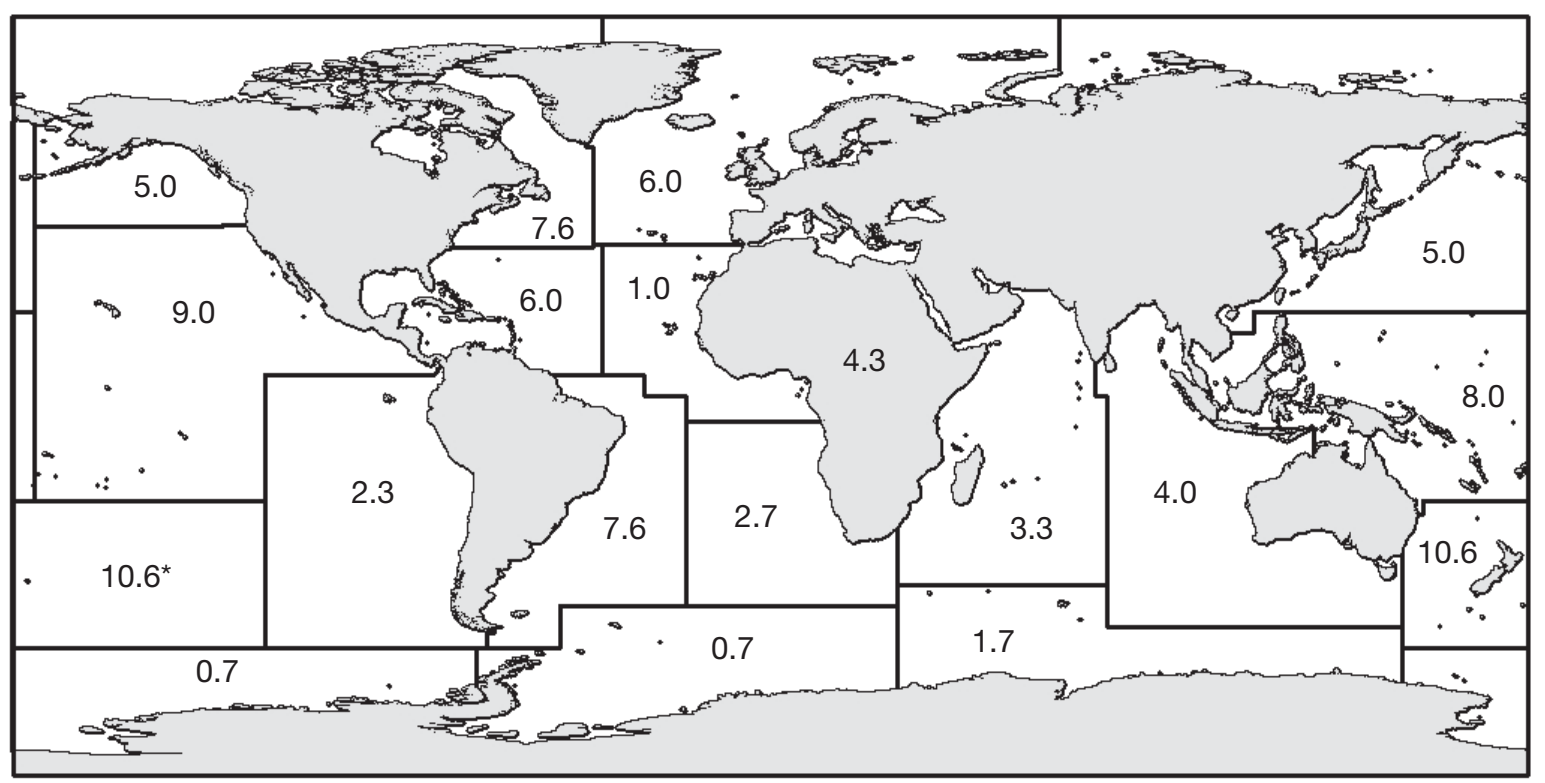

Fig. 2. Proportional distribution (\%) of global bycatch research published in peer-reviewed journals. The studies identified by the search criteria described in Fig. $1(\mathrm{n}=301)$ were assigned to Food and Agriculture Organization (FAO) statistical regions (Carocci 2008), with each study that spanned 2 or 3 regions being counted once in each of the regions. Several lab and theoretical studies could not be assigned to a region, while 44 studies (14.6\%) were global in scope and are not included in the map. The FAO statistical regions are as follows: western North Pacific, eastern North Pacific, western Central Pacific, eastern Central Pacific, western South Pacific, eastern South Pacific, western North Atlantic, eastern North Atlantic, western Central Atlantic, eastern Central Atlantic, western South Atlantic, eastern South Atlantic, western Indian, eastern Indian, Pacific Antarctic, Atlantic Antarctic, Indian Antarctic, and Mediterranean

research effort does not reflect the global distribution of fishing effort. As such, vast areas of the ocean remain unstudied, with little knowledge of bycatch on a global scale.

(2) Which threatened species are taken as bycatch? Whereas scores of sea turtle, seabird, and marine mammal species are incidentally caught in marine fisheries, research to date has focused on a small subset of those species. Furthermore, the distribution of bycatch research is uneven among species and taxa (Table 1). Consequently, our knowledge of which species are affected by bycatch, and to what degree, is incomplete.
(3) Which fisheries and gear types result in the highest bycatch of marine megafauna? Large-scale industrial fisheries have received the lion's share of attention, with research focusing on trawls, longlines, and high-seas gillnets (Table 1). These fisheries are more amenable to research due to the limited number of vessels involved (relative to artisanal and small-scale fisheries). Moreover, a few cases have been highly publicized (e.g. dolphins in the tuna purse-seine fisheries, sea turtles in shrimp trawls, albatrosses in longlines). Nevertheless, recent evidence is linking artisanal fisheries and bycatch of threatened species (Godley et al. 1998, Jaramillo-Legorreta et al. 2007, Peckham et al.

Table 1. Percentage of studies for the different non-fish bycatch taxa by gear type (based on the literature search described in Fig. 1). Studies involving multiple taxa were counted once for each taxon. Likewise, studies involving multiple gear types were counted once for each gear type. General: overarching studies that did not address a specific taxon or gear type; NA: taxonspecific studies that did not focus on gear types and gear-specific studies that did not focus on taxa

\begin{tabular}{|lcccccccc|}
\hline & Hook-line & Purse-seine & Passive net & Trap & Towed gear & General & NA & Total \\
\hline Marine mammal & 1.9 & 3.3 & 16.5 & 1.4 & 4.9 & 3.8 & 1.4 & 33.2 \\
Marine reptile & 7.4 & 1.1 & 4.9 & 1.6 & 10.4 & 3.6 & 1.1 & 30.2 \\
Seabird & 18.1 & 0.5 & 5.8 & 0.0 & 4.4 & 1.9 & 0.5 & 31.3 \\
General & 0.0 & 0.3 & 0.0 & 0.0 & 0.3 & 3.3 & 0.0 & 3.8 \\
NA & 0.0 & 0.0 & 0.0 & 0.0 & 0.0 & 1.4 & 0.0 & 1.4 \\
Total & 27.5 & 5.2 & 27.2 & 3.0 & 20.1 & 14.0 & 3.0 & 100.0 \\
\hline
\end{tabular}


2007). These reports suggest bycatch of such a magnitude that mitigation efforts cannot overlook the effects of small-scale fisheries.

(4) What are the population-level effects on bycatch species? The population-level consequences of bycatch vary across species, fisheries, and geographic regions. In general, the megafauna discussed in this issue mature relatively late in life and have low annual reproductive rates, depending on long-lived individuals (high adult survival rates) for population growth and stability. Such species with 'slow' life histories are particularly vulnerable to mortality caused by human activities (Heppell et al. 2000). However, some populations are under heavier pressure from fisheries or less resilient to a given level of mortality than others. Owing to the difficulties of estimating demographic parameters for long-lived species that, in many cases, are also highly migratory and have broad oceanographic distributions, our ability to predict vulnerability to bycatch effects remains limited.

(5) How can bycatch of threatened species be reduced? There has been clear progress in bycatch mitigation for particular gear types in some countries. However, technology/knowledge transfer and adoption of successful mitigation practices among fleets requires strong political support, something that is slow or lacking in many nations. Furthermore, the majority of the mitigation resources have focused on techniques and technologies, and relatively little effort has gone toward post-implementation monitoring or the study of the social and legal framework that surround efforts to reduce bycatch (Campbell \& Cornwell 2008 , this Theme Section). Although difficult, integrating these approaches into a comprehensive bycatch mitigation program is essential, as it allows researchers to identify context-specific issues that contribute to successful mitigation (Cox et al. 2007).

The 23 papers presented in this Theme Section of Endangered Species Research provide encouraging examples of conservation progress while highlighting the need for continued research. Specifically, the studies draw attention to several emerging issues, including artisanal fisheries bycatch, the demographic effects of bycatch, and the need for comprehensive, trans-national mitigation efforts. In the sections that follow, we discuss how the studies included in this Theme Section contribute to answering key bycatch questions.

\section{Where is bycatch of threatened species most prevalent?}

Basic fisheries data (e.g. fishing effort and landings of target catch) vary in their quality and availability, impeding the comprehensive study of bycatch. Major information gaps exist for important fisheries of both industrialized and developing nations (Kelleher 2005), for distant water fleets operating within foreign exclusive economic zones (EEZs) and on the high seas (Kaczynski \& Fluharty 2002, Xue 2006), and for intergovernmental fisheries management organizations (e.g. Fromentin 2003, Levesque 2008). Fisheries data are also widely misreported (Watson \& Pauly 2001), and illegal, unreported, and unregulated (IUU) fisheries are responsible for unknown but potentially high levels of bycatch around the globe ( $\mathrm{Nel}$ et al. 2002, Sumaila et al. 2006).

Information gaps on bycatch are even larger, as relatively few fisheries around the world have onboard observer programs to collect at-sea data on discarded non-target catch (Kelleher 2005). Many regions lack even anecdotal accounts of bycatch in the form of beach monitoring programs or fisheries surveys. These factors contribute to the uneven geographic distribution of bycatch studies (Fig. 2), highlighting the need for additional bycatch monitoring and research, particularly in underrepresented areas.

The question of where bycatch is occurring can be framed along different spatial scales. In addition to the most basic need for more information about which species or populations (and how many) are being affected by bycatch in different ocean areas, finer-scale information on the spatiotemporal distribution of where the gear interactions occur is obviously important (Lewison et al. 2004b). Using opportunistic sightings of shorttailed albatrosses in the North Pacific, Zador et al. (2008b, this Theme Section) modeled the distribution of this elusive bird and compared it with the distribution of the Alaskan groundfish trawl fleet. The results suggest that overlap between albatrosses and the fishery varies as a function of season, fishing sector, method used to predict albatross distribution, and metrics used to calculate overlap. This represents an important step towards determining when and where short-tailed albatross-fishery interactions are most likely to occur.

Similarly, Petersen et al. (2008, this Theme Section) used satellite telemetry to track black-browed and white-capped albatrosses off the coast of South Africa. Using generalized linear models, they investigated the distribution of albatrosses compared to that of trawlers and longline vessels, and to coastal bathymetry. Their results suggest that white-capped albatrosses spend considerably more time along the continental shelf and shelf break than black-browed albatrosses, overlapping more with trawl fisheries that also concentrate in this region. Nevertheless, both species show a significant relationship between time spent in a given area and the amount of fishing activity in that area, highlighting the potential for bycatch interactions and the need for mitigation. 
In a finer-scale example, Alfaro Shigueto et al. (2008, this Theme Section), found that the distribution of loggerhead turtles off the coast of Peru is spatially structured and, as a result, gear in deeper water, far from shore, posed the greatest risk to turtles. This suggests that certain fisheries are more likely to catch loggerheads than others, but it also points to how the impact of fishing gear can vary depending on circumstances. Specifically, longline vessels that venture into deeper waters are much more likely to encounter loggerheads than nearshore gillnet vessels.

Consideration of important environmental factors can help predict the distribution of bycatch species. Braun-McNeill et al. (2008, this Theme Section) used sea surface temperature (SST) measurements along the east coast of the USA to model seasonal changes in the distribution of cheloniid sea turtles. Their assumption that cheloniid sea turtles are physiologically limited to waters above a certain temperature range makes it possible to predict when these turtles will travel north along the Atlantic coast in spring and back south in fall. Thus, managers can plan spatio-temporal closures for those fisheries known to interact with threatened sea turtles along the US Atlantic coast. In a similar vein, Howell et al. (2008, this Theme Section) developed a software product based on SST to reduce loggerhead-gear interactions in the Hawaii-based pelagic longline fishery. The product, called TurtleWatch, recommends that fishers avoid areas colder than the $18.5^{\circ} \mathrm{C}$ isotherm during the first quarter of the year to reduce sea turtle bycatch. These recommendations proved accurate. During a field trial, most loggerhead bycatch occured in areas fishers were advised to avoid.

Incorporating additional parameters, Gardner et al. (2008, this Theme Section) used a Bayesian approach to model bycatch of loggerhead and leatherback sea turtles in the western North Atlantic. Their model suggests that longline bycatch of loggerheads is affected by bottom depth, SST, and fishing method, whereas bycatch of leatherbacks is only influenced by fishing method. Additionally, the work of Gardner et al. (2008) indicates that bycatch patterns vary across ocean areas, highlighting the need for spatially-explicit management decisions.

Even without predictor variables, researchers can study the distribution of bycatch using data from fishers' logbooks or collected by onboard observers. Past efforts have used plots of raw bycatch rates to designate marine protected areas or time-area closures, ignoring the distribution of fishing effort and target catch yields, the distribution of other bycatch taxa, and the extensive body of statistical methods developed for analyzing spatial patterns. Noting these oversights, Lewison et al. (in press) demonstrate the utility of basic spatial statistics for the study of bycatch, highlighting insights that emerge when other bycatch taxa, fishing effort, and target catch are integrated into the analysis.

\section{Which threatened species are taken as bycatch?}

The diversity of species affected by bycatch is still largely unknown in many parts of the world (Table 1; Fig. 2). Many of these knowledge gaps can be attributed to a lack of taxonomic expertise and research funding, as is the case for many developing nations where basic lists of species that occur or are caught by fishers are incomplete (e.g. marine mammals in West Africa; Perrin \& Van Waerebeek 2007). Other factors, such as conservation status and policy-related mandates also play a role in shaping the imbalance of our knowledge across taxa (Moore et al. in press).

The papers in this Theme Section are no exception to the trend reported above, with 10 studies on sea turtles (Alfaro Shigueto et al. 2008, Braun-McNeill et al. 2008, Crognale et al. 2008, Gardner et al. 2008, Gless et al. 2008, Grantham et al. 2008, Howell et al. 2008, Peckham et al. 2008, Southwood et al. 2008, and Tomás et al. 2008), 7 studies on birds (Anderson et al. 2008, Benjamins et al. 2008, Bugoni et al. 2008, Gilman et al. 2008, Grantham et al. 2008, Petersen et al. 2008, and Zador et al. 2008b), and 5 studies on marine mammals (Brotons et al. 2008, Campbell et al. 2008, Chilvers 2008, Karamanlidis et al. 2008 and Scheidat et al. 2008). Even without consideration of the number of species in each taxon, the distribution of research effort presented here is clearly skewed (though this may in part be due to elevated awareness of Endangered Species Research and this issue in the sea turtle research community).

Sharks and rays are another group of concern, with many species and populations declining as a result of unintentional capture in fishing gear (Baum et al. 2003). Very little is known about the distribution and abundance of most species. However, the limited data that exist on elasmobrach life histories indicate that many have low reproductive potential, making them especially vulnerable to bycatch (Stevens et al. 2000).

As we work to fill knowledge gaps on the diversity of species affected by bycatch, it will be worthwhile to do so at the community rather than the species level. An emerging frontier in bycatch research builds on the recognition that one gear type usually impacts multiple species. Multi-species approaches to research and conservation are both logistically and analytically more difficult, but offer a more comprehensive understanding of the problem and are likely to lead to more efficient data gathering and more effective management schemes. For example, Baum et al. (2003) noted the potential for unintended negative consequences as 
a result of single-species management efforts. They argued that the designation of protected areas for certain species of bycatch in the North Atlantic would result in the displacement of fishing effort to areas favored by other species, effectively shifting the bycatch problem from one group to another.

A multi-species example from this Theme Section is the study by Grantham et al. (2008), in which multiple bycatch taxa (birds, sea turtles, and sharks) were considered in deciding which of 3 approaches to bycatch reduction was most effective. The approaches that were compared included region-wide temporal closures, small-scale spatial closures, and small-scale temporal closures. There was variation in where and when different species were caught as bycatch, and it was determined that temporary area closures were the best strategy as they achieved the same conservation objectives for bycatch species as the other types of closures, but had less impact on the longline fishery.

\section{Which fisheries and gear types result in the highest bycatch of marine megafauna?}

Bycatch research has mostly targeted industrial fisheries, overlooking the potential effects of small-scale artisanal fisheries on threatened species. While understandable from a logistic point of view (i.e. it is much easier to study a few large ships than many small boats), this restricted focus will no longer suffice. A growing body of evidence documents high bycatch of threatened species by artisanal fisheries (Godley et al. 1998, Jaramillo-Legorreta et al. 2007, Peckham et al. 2007). Several of the articles in this Theme Section deal either directly with the bycatch of threatened species by artisanal fisheries (Alfaro Shigueto et al. 2008, Peckham et al. 2008) or with mitigation strategies targeted towards small-scale fishing operations (Brotons et al. 2008).

The work of Alfaro Shigueto et al. (2008) suggests that artisanal longline fishers off the coast of Peru capture considerable numbers of South Pacific loggerhead turtles, potentially endangering this population. Encouragingly, however, nearly all of the turtles are retrieved alive, meaning that proper training in release techniques could reduce turtle mortality from this fishery. The study by Peckham et al. (2008) shows that small-scale fisheries can be extremely lethal; bycatch in small-scale fisheries off the coast of northwestern Mexico threatens Pacific loggerheads and amounts to the highest bycatch rates reported.

As a means to mitigate artisanal fisheries bycatch, Brotons et al. (2008) examined whether pingers reduce interactions between bottlenose dolphins and an artisanal gillnet fishery off the Balearic Islands in the
Mediterranean. They report a reduction in dolphin activity near nets with active pingers, along with a modest increase in target catch per unit effort. However, they caution that their results are based on a single year of research and may not be sufficiently robust to justify the high costs associated with pinger deployment on all nets in the fishery.

Even for industrial fisheries, serious issues continue to emerge (e.g. seabirds and deep-water trawl fisheries; Baker et al. 2007, Watkins et al. 2008), and entire regions remain where bycatch in industrial fleets has never been monitored. Recognizing this data gap, Benjamins et al. (2008) estimated bycatch of seabirds in different gillnet fisheries around Newfoundland and Labrador. Although current mortality rates do not appear to threaten the seabirds they studied, certain sub-populations may be jeopardized by high bycatch near breeding colonies. Also, Benjamins et al. (2008) draw attention to the fact that many species migrate long distances over the course of a year, encountering multiple fisheries over time. Mortality rates for each fishery must be taken into account when assessing the population-level effect of bycatch on vagile species.

\section{What are the population-level effects on bycatch species?}

As a result of the challenges associated with estimating demographic parameters for sea turtles, seabirds, and marine mammals, we know relatively little about where or for which species the effects of bycatch pose the greatest threat to population viability (Fig. 3). This knowledge gap poses important dilemmas for natural resource managers. Without a clear indication of whether an observed level of bycatch is unsustainable, it may be difficult to spur adequate conservation action where it is needed. Alternatively, where wildlife conservation is an important management priority, uncertainty about the population impacts of bycatch could lead to unnecessary conservation actions that negatively affect fishers. A recent debate serves to illustrate this point: using what limited data were available, Slooten (2007a) argued that bycatch in commercial gillnets has reduced the Hector's dolphin population off the coast of New Zealand to $27 \%$ of the 1970 population estimate, and that the decline will continue over the next few decades if current management practices continue. Population recovery in a timely manner will require that bycatch be reduced to zero for this species, something that would only be possible if those fishing methods that result in bycatch (commercial and recreational gillnets, trawls) were banned in areas where these dolphins live. A second study, using the same limited data set, came to a very different conclu- 


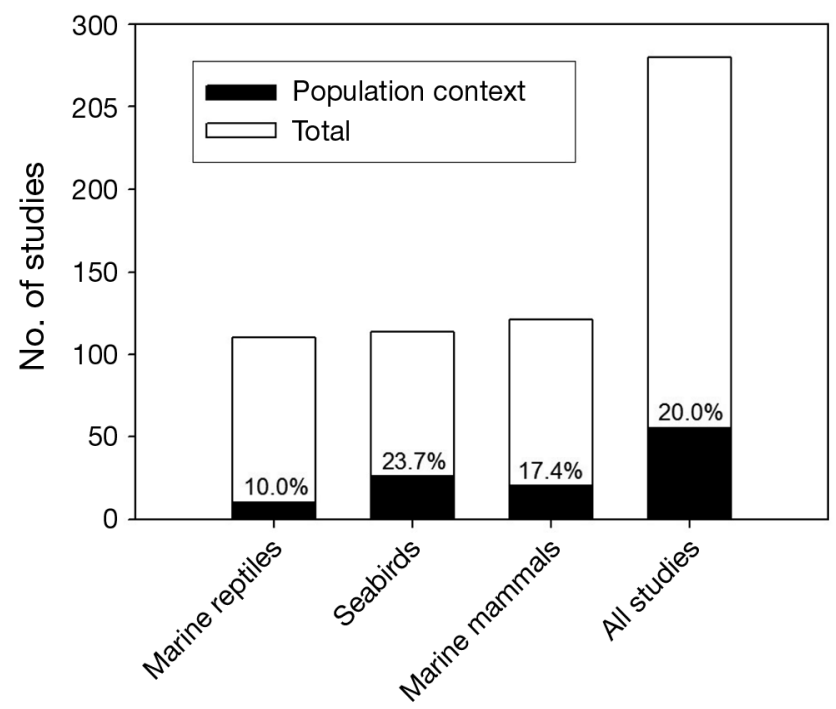

Fig. 3. Number of studies for 3 focal taxonomic groups (based on the literature search described in Fig. 1) and the number and percentage of those studies that put bycatch into a population context. For the purposes of our analysis, we defined population context as any study that did one or more of the following things: (1) estimated the demographic effects of bycatch directly; (2) estimated the demographic effects of bycatch through indirect or correlative approaches; (3) evaluated the relative effects of different fisheries on a species, or of a particular fishery on different species; or (4) explicitly considered population biology in conducting the study

sion: Middleton et al. (2007) infer that Hector's dolphin populations are stable (but see Slooten 2007b).

In this Theme Section, the paper by Chilvers (2008) on the endangered New Zealand sea lion exemplifies the value of evaluating bycatch in a population context. In spite of strong protection by law, detailed demographic studies indicate a 30\% decline in pup production since 1998, suggesting that current management efforts are not sufficient. Likewise, Anderson et al. (2008) used a stochastic matrix model to estimate the population trajectory of waved albatrosses. They demonstrate a convincing decline in abundance which they link to reduced adult survival as a result of bycatch in the Peruvian artisanal longline fishery.

Recognizing the importance of population size estimates for the management of bycatch, Scheidat et al. (2008) used line-transect aerial surveys to estimate harbor porpoise abundance in the southwestern Baltic Sea. Comparing their results with estimates of bycatch, the authors conclude that bycatch rates exceed management recommendations and call for improved monitoring of bycatch and efforts to mitigate its effects.

Clearly, there needs to be a greater research emphasis on evaluating bycatch in a population-level context to help resolve management dilemmas (Heppell et al. 2000). Moreover, given the financial and logistical obstacles to investigating bycatch in all the world's fisheries, thinking about the problem from a population-level perspective will help identify how best to allocate limited resources. However, assessing the population-level consequences of bycatch is extremely challenging. Doing so in a direct fashion first requires estimating how many individuals in a population are killed across the fisheries they encounter. To do this accurately, onboard observer programs are required, which in some cases are impractical to implement due to factors such as cost, time, safety, logistics, and nonparticipation by fishers. Moreover, bycatch is a multifishery (sometimes multi-national) problem for many species, highlighting the need to develop trans-jurisdiction partnerships between researchers and governments to address the issue. Even where these challenges can be overcome, knowing whether a given level of incidental mortality is sustainable requires additional information about population trends or size (e.g. whether the population is decreasing and what percentage of the population is removed) and/or potential population growth (e.g. whether the population can handle a $5 \%$ removal). Obtaining direct information about the impacts of bycatch on populations in this way is typically not feasible; the data to estimate the required parameters can not be collected.

These challenges demand that creative approaches be devised to assess the demographic impacts of bycatch through indirect means. A number of casespecific examples demonstrate attempts to maximize inference based on limited information (Heppell et al. 2000, Dillingham \& Fletcher 2008, Zador et al. 2008a, Moore \& Read in press). Additionally, more general frameworks have been developed with potential application in a variety of fisheries or for different taxa (Véran et al. 2007, Dillingham \& Fletcher 2008, Snover \& Heppell in press). These frameworks vary in their data requirements and outputs, but all provide some measure of insight into the possible effects of bycatch on populations. For example, in the USA, marine mammal bycatch is managed based on estimating the potential biological removal (PBR) of different mammal stocks. This is a fairly data-intensive framework, but it is standardized, is based on precautionary principles, is designed to account for uncertainty in various demographic estimates, and defaults to a rule-ofthumb value of potential population growth $(4 \%)$ for stocks with insufficient data to estimate this parameter (Wade 1998, Taylor et al. 2000). As such, it has proven effective for identifying where in the USA bycatch is, and where it is not, likely to be a conservation problem. In another example, Wallace et al. (2008) noted that added mortalities at different life stages have unequal consequences for populations. Using an analysis based on relative reproductive values and bycatch rates of loggerheads in different geographic 
areas, they were able to highlight the global fisheries most (and least) likely to have negative demographic consequences for this species. In this Theme Section, Alfaro Shigueto et al. (2008) similarly addressed bycatch in a population context, by evaluating the size of loggerheads captured in Peruvian artisanal fisheries in terms of their probable life stages.

Although threatened populations are a high priority, researchers should not overlook the value of monitoring species not currently declining fisheries bycatch. Such data provide a baseline for future comparison, reducing the likelihood that emergent threats (e.g. changes in climate, fishing activity, etc.) would go unnoticed.

\section{How can bycatch of threatened species be reduced?}

The study of bycatch mitigation efforts can be divided into 4 related categories: species ecology and behavior, bycatch mitigation techniques and technologies, the social and legal framework that surround efforts to reduce bycatch, and post-implementation monitoring. A better understanding of the behavior and ecology of the species involved may help reduce bycatch encounters. Southwood et al. (2008) review auditory, chemical, and light-based methods for reducing sea turtle bycatch in longline fisheries, focusing on the detection abilities of pelagic fishes and sea turtles. Based on existing knowledge, they argue that visual (and, to a lesser degree, chemical) cues are the most effective venue for future research.

An example of such work is the study by Gless et al. (2008) on behavioral responses of post-hatchling leatherbacks to lightsticks and LEDs of different colors. Lights are commonly attached to longlines to attract target species such as swordfish, but may serve as a visual attractant for sea turtles as well. To test this hypothesis, the authors exposed juvenile leatherbacks to lights of different colors in a laboratory setting. Their results suggest that young leatherbacks do not orient towards different colors or types of light stimuli, in contrast with laboratory studies of loggerheads, which indicate a positive response to light.

In a similar vein, Crognale et al. (2008) explored the visual capacity of adult leatherbacks in a field setting using non-invasive electrophysiology. The results suggest that leatherbacks are low-light, short wavelength specialists that have poor temporal resolution of visual stimuli. These findings may be useful for designing lightsticks that lure target species, such as swordfish, without attracting leatherbacks.

There are many examples of modifications to fishing gear and/or fishing techniques to reduce bycatch. For example, Gilman et al. (2008) review methods for reducing seabird bycatch, taking into consideration both the effectiveness of seabird bycatch reduction techniques and the likelihood that they will be implemented by the Hawaii-based longline tuna fishery. Although all of the techniques they review have proven to be effective at reducing seabird bycatch, Gilman et al. (2008) note that side-setting of gear is often used in places where not required by law because fishers find that it offers some advantages over stern-setting. Gilman et al. (2008) note that post-implementation monitoring of the fishery reveals that seabird bycatch has declined by $83 \%$, demonstrating general consistency with experimental results on the efficacy of relevant seabird avoidance methods.

This example highlights the need for post-implementation monitoring of bycatch mitigation efforts. Even when gear modifications successfully reduce bycatch under experimental conditions, they do not always work as expected once implemented fleetwide (Cox et al. 2007). Successful mitigration involves collaboration between scientists, managers, and the fishers involved, as well as education and outreach, enforcement, and incentives for fishers to implement the approaches appropriately. Unfortunately, the review by Campbell \& Cornwell (2008) found that most mitigation studies are focused on technical design and experimental performance of bycatch reduction technologies (BRTs). Far less has been written about the human and institutional context of BRTs. Instead, researchers often assume that fishers will use BRTs if certain conditions are met: (1) there are economic incentives for the use of BRTs; (2) there is adequate enforcement of laws mandating the use of BRTs; and (3) fishers are encouraged to participate in the process of developing BRTs. These assumptions have rarely been tested, revealing a gap in our knowledge about bycatch mitigation that can be addressed with the help of social scientists. The important role that the study of social and economic factors plays within bycatch research is highlighted by a study by Prellezo \& Gallastegui (2008, this Theme Section). The authors provide an economic perspective on bycatch reduction through gear selectivity by modeling fishers' behavior based on a mixed fishery composed of target and bycatch species. Their work suggests that fisheries management based on total allowable catch (TAC) is effective, but will differ depending on whether TAC of all species is aggregated or regulated separately.

While few studies span all 4 categories described above (species ecology, bycatch mitigation, social framework, and monitoring), efforts to reduce bycatch depend on due consideration of each one of them. More specifically, managers must integrate 
information from diverse sources in order to maximize the likelihood that mitigation efforts succeed. A comprehensive study by Campbell et al. (2008) demonstrates the utility of such a multi-pronged approach. The authors combined information on incidental mortality of Australian sea lions in the west coast rock lobster fishery with a population viability analysis for each breeding colony to demonstrate that current levels of bycatch will lead to further population decline. They then use satellite telemetry and time-depth information to inform the designation of management areas in which sea lion excluder devices (SLEDs) should be used. The authors further provide details on the evaluation of several SLED designs and a field trial demonstrating that bycatch of sea lions can be mitigated without adversely affecting the catch of rock lobsters. Moreover, preliminary results suggest a very high level of compliance (95\%) among fishers.

The articles in this issue illustrate the many opportunities for science to inform bycatch reduction efforts. These include, but are not limited to: (1) the design and interpretation of gear mitigation trials; (2) the study of bycatch species behavior and ecology; (3) the statistical analysis of spatio-temporal patterns in bycatch; (4) the design of post-implementation monitoring schemes; and (5) the study of social, legal, and economic aspects of bycatch mitigation. Participatory research that engages fishers in bycatch reduction has proven to be very successful and offers a silver lining to the bycatch dilemma (e.g. Hall \& Mainprize 2005, Peckham et al. 2007). Specifically, modest modifications of fishing practices (reduced effort, changes in methods, etc.) can dramatically reduce bycatch mortality (Peckham et al. 2008, Shigueto et al. 2008).

\section{Overcoming current obstacles}

Unfortunately, logistic and financial constraints often impede the study of bycatch. This necessitates the use of indirect measures that may be obtained from stranding data (Caillouet et al. 1996, Žydelis et al. 2006, Moore \& Read in press), port-based observations and surveys (Ilangakoon et al. 2008), and fishers' logbooks (Baum et al. 2003). Although subject to potential bias, such indirect sources of data provide a useful complement to more costly, observer-based methods for the study of bycatch. For example, Peckham et al. (2008) paired stranding data with bycatch observations to strengthen their argument that high bycatch in the longline and gillnet fisheries off the coast of Baja California represents a major source of mortality for loggerheads in the North Pacific. The stranding rates they recorded are the highest ever reported and draw attention to the immediate need to reduce bycatch in this part of the world. Along similar lines, Tomás et al. (2008) used stranding data along the east coast of Spain to study sea turtle bycatch. Their findings, based on a $14 \mathrm{yr}$ monitoring period, suggest that interactions with fisheries, particularly longlines, are the main cause of loggerhead strandings in the Western Mediterranean. In an effort to determine threats to the critically endangered Mediterranean monk seal, Karamanlidis et al. (2008) combined data from necropsies on stranded individuals, fisheries surveys, and the literature. Their efforts suggest that entanglement in static nets poses a threat to the seals, with sub-adults being especially vulnerable to bycatch in fishing gear.

A second challenge confronting bycatch researchers is the diffuse distribution of existing knowledge in the literature. Combined with the aforementioned logistic/financial constraints, this suggests a role for synthetic analyses to bring data together and help identify conservation and management priorities. At the same time, such an effort will draw attention to those communities, species, or populations that have yet to be studied. For example, in addition to reporting bycatch rates for seabirds in the Brazilian pelagic longline fishery, Bugoni et al. (2008) reviewed bycatch studies for the southwestern Atlantic as a whole, putting their results into a regional context and providing a baseline for assessing the efficacy of mitigation efforts.

The synthesis of current knowledge on bycatch will also provide a foundation for management and conservation efforts that target unstudied and understudied species, regions, and gear types. This stands as a third major obstacle facing those working on the problem - given the context-dependent nature of bycatch, how can we apply what we have learned from specific case studies to unknown situations? A number of approaches should be explored, including efforts to correlate bycatch with oceanographic variables (Gardner et al. 2008), an analysis of the ecological correlates of bycatch vulnerability (Moore et al. 2008), and other as yet unexplored analyses.

It must be recognized that no synthesis or quantitative method, however sophisticated, can compensate for a complete lack of data - as the saying goes: 'garbage in equals garbage out'. Thus, the approaches described in this section should be seen as complementing, rather than supplanting, the collection of data using costly, but accurate observer-based methods and case studies (Epperly et al. 2007). Only by advancing understanding on multiple fronts can we hope to comprehensively address the issue of fisheries bycatch of marine megafauna. 


\section{Advancing science, reducing bycatch}

In conservation, finding the balance between research and action is an ever-present challenge; the price of a mistake could be species extinction, the inefficient use of limited conservation funds, or unnecessary constraints on resource use. Bycatch research has advanced considerably over the past few decades, providing valuable guidance for selected management and conservation efforts. With sufficient data on population metrics and the distribution of bycatch events, researchers can explore the economic and conservation tradeoffs associated with alternative management approaches (Wilcox \& Donlan 2007). Furthermore, if no viable alternatives exist, research provides a justification for making difficult management decisions (Finkelstein et al. 2008). Without the insights provided by further bycatch research, efforts to prioritize areas, times, fisheries, and/or species for conservation purposes may be inefficient or even counterproductive. The study of bycatch can also help us to avoid negative unintended consequences that occasionally occur as a result of displaced fishing effort (Hall 1998, Baum et al. 2003), a switch in target species, and changes in gear or fishing techniques (Hall 1998, Weimerskirch et al. 1999).

Nevertheless, it must be recognized that fisheries bycatch of marine megafauna is a global issue involving innumerable fisheries interacting with scores of bycatch species. The scope of the problem exceeds our current understanding. Limited funding means that further progress cannot depend entirely on accumulating more case studies. While additional system-specific surveys and monitoring are essential, synthetic research offers the potential to apply what has been learned from well-studied systems to less-studied regions or fisheries, and to more strategically direct management and conservation efforts.

The articles in this Theme Section are diverse, yet each of them addresses bycatch research priorities: redressing the uneven distribution of bycatch research in terms of geography, fisheries, gear types, and bycatch species; putting bycatch rates into a population context through the incorporation of demographic data; and recognizing the need for comprehensive bycatch mitigation efforts. Moreover, the contributions demonstrate that reducing bycatch of vulnerable populations requires attention and action on many fronts. This includes collaborative programs with fishers and fishing communities (e.g. the Inter-American Tropical Tuna Commission-led initiative to reduce sea turtle bycatch; Mug et al. 2008), increased education and outreach (Macys \& Wallace 2003, Young et al. 2006), and coordinated policy and policing at local, national, and international levels (Crawford \& Cooper 2003).
Research alone will not suffice, but it represents an essential element in the effort to reduce bycatch of marine megafauna on a global scale.

Acknowledgements. We thank Project GloBAL, funded by a grant from the Gordon and Betty Moore Foundation, for financial and intellectual support with the development of this manuscript. We also thank B. Godley, H. Peckham, and the Project GloBAL team for comments on earlier versions of the manuscript.

\section{LITERATURE CITED}

Alfaro Shigueto J, Mangel JC, Seminoff JA, Dutton PH (2008) Demography of loggerhead turtles Caretta caretta in the southeastern Pacific Ocean: fisheries-based observations and implications for management. Endang Species Res 5:129-135

Anderson DJ, Huyvaert KP, Awkerman JA, Proaño CB, Milstead WB, Jiménez-Uzcátegui G, Cruz S, Grace JK (2008) Population status of the Critically Endangered waved albatross Phoebastria irrorata, 1999 to 2007. Endang Species Res 5:185-192

Arnold JM, Brault S, Croxall JP (2006) Albatross populations in peril: a population trajectory for black-browed albatrosses at South Georgia. Ecol Appl 16:419-432

Baker GB, Double MC, Gales R, Tuck GN and others (2007) A global assessment of the impact of fisheries-related mortality on shy and white-capped albatrosses: conservation implications. Biol Conserv 137:319-333

Barlow J, Cameron GA (2003) Field experiments show that acoustic pingers decrease marine mammal bycatch in the California drift gill net fishery. Mar Mamm Sci 19:265-283

Baum JK, Myers RA, Kehler DG, Worm B, Harley SJ, Doherty PA (2003) Collapse and conservation of shark populations in the Northwest Atlantic. Science 299:389-392

Beddington JR, Agnew DJ, Clark CW (2007) Current problems in the management of marine fisheries. Science 316:1713-1716

Benjamins S, Kulka DW, Lawson J (2008) Incidental catch of seabirds in Newfoundland and Labrador gillnet fisheries, 2001-2003. Endang Species Res 5:149-160

- Braun-McNeill J, Sasso CR, Epperly SP, Rivero C (2008) Feasibility of using sea surface temperature imagery to mitigate cheloniid sea turtle-fishery interactions off the coast of northeastern USA. Endang Species Res 5:257-266

Brotons JM, Munilla Z, Grau AM, Rendell L (2008) Do pingers reduce interactions between bottlenose dolphins and nets around the Balearic Islands? Endang Species Res 5:301-308

Bugoni L, Mancini PL, Monteiro DS, Nascimento L, Neves TS (2008) Seabird bycatch in the Brazilian pelagic longline fishery and a review of capture rates in the southwestern Atlantic Ocean. Endang Species Res 5:137-147

Bull LS (2007) Reducing seabird bycatch in longline, trawl, and gillnet fisheries. Fish Fish 8:31-56

Bundy A, Chuenpagdee R, Jentoft S, Mahon R (2008) If science is not the answer, what is? An alternative governance model for the world's fisheries. Front Ecol Environ 6: 152-155

Caillouet CWJ, Shaver DJ, Teas WG, Nance JM, Revera DB, Cannon AC (1996) Relationship between sea turtle stranding rates and shrimp fishing intensities in the northwestern Gulf of Mexico: 1986-1989 versus 1990-1993. Fish 
Bull (Wash DC) 94:237-249

Campbell LM, Cornwell ML (2008) Human dimensions of bycatch reduction technology: current assumptions and directions for future research. Endang Species Res 5:325-334

Campbell R, Holley D, Christianopoulos D, Caputi N, Gales N (2008) Mitigation of incidental mortality of Australian sea lions in the west coast rock lobster fishery. Endang Species Res 5:345-358

Carocci F (2008) Fishing areas for statistical purposes. In: CWP handbook of fishery statistical standards, Section $\mathrm{H}$, Food and Agriculture Organization of the United Nations, Fisheries and Aquaculture Department, Rome. Available at: www.fao.org/fishery/cwp/handbook/H

Chilvers BL (2008) New Zealand sea lions Phocarctos hookeri and squid trawl fisheries: bycatch problems and management options. Endang Species Res 5:193-204

Cox TM, Lewison RL, Žydelis R, Crowder LB, Safina C, Read AJ (2007) Comparing effectiveness of experimental and implemented bycatch reduction measures: The ideal and the real. Conserv Biol 21:1155-1164

Crawford RJM, Cooper J (2003) Conserving surface-nesting seabirds at the Prince Edward Islands: The roles of research, monitoring and legislation. Afr J Mar Sci 25: $415-426$

Crognale MA, Eckert SA, Levenson DH, Harms CA (2008) Leatherback sea turtle Dermochelys coriacea visual capacities and potential reduction of bycatch by pelagic longline fisheries. Endang Species Res 5:249-256

> Dankel D, Skagen D, Ulltang O (2008) Fisheries management in practice: review of 13 commercially important fish stocks. Rev Fish Biol Fish 18:201-233

Dillingham PW, Fletcher D (2008) Estimating the ability of birds to sustain additional human-caused mortalities using a simple decision rule and allometric relationships. Biol Conserv 141(7):1783-1792

Epperly SP, Braun-McNeill J, Richards PM (2007) Trends in catch rates of sea turtles in North Carolina, USA. Endang Species Res 3:283-293

Finkelstein M, Bakker V, Doak DF, Sullivan B and others (2008) Evaluating the potential effectiveness of compensatory mitigation strategies for marine bycatch. PLoS One 3:e2480

Fromentin JM (2003) The east Atlantic and Mediterranean bluefin tuna stock management: uncertainties and alternatives. Sci Mar 67(Suppl 1):51-62

Gardner B, Sullivan PJ, Epperly S, Morreale SJ (2008) Hierarchical modeling of bycatch rates of sea turtles in the western North Atlantic. Endang Species Res 5:279-289

Gilman E, Brothers N, Kobayashi DR (2007) Comparison of three seabird bycatch avoidance measures in Hawaiibased pelagic longline fisheries. Fish Sci 73:208-210

Gilman E, Kobayashi D, Chaloupka M (2008) Reducing seabird bycatch in the Hawaii longline tuna fishery. Endang Species Res 5:309-323

Gless JM, Salmon M, Wyneken J (2008) Behavioral responses of juvenile leatherbacks Dermochelys coriacea to lights used in the longline fishery. Endang Species Res 5: 239-247

Godley BJ, Gucu AC, Broderick AC, Furness RW, Soloman SE (1998) Interaction between marine turtles and artisanal fisheries in the Eastern Mediterranean: A probable cause for concern? Zool Middle East 16:49-64

> Grantham HS, Petersen SL, Possingham HP (2008) Reducing bycatch in the South African pelagic longline fishery: the utility of different approaches to fisheries closures. Endang Species Res 5:291-299
Hall MA (1998) An ecological view of the tuna-dolphin problem: impacts and tradeoffs. Rev Fish Biol Fish 8:1-34

Hall SJ, Mainprize BM (2005) Managing by-catch and discards: How much progress are we making and how can we do better? Fish Fish 6:134-155

Heppell SS, Caswell H, Crowder LB (2000) Life histories and elasticity patterns: perturbation analysis for species with minimal demographic data. Ecology 81:654-665

> Howell EA, Kobayashi DR, Parker DM, Balazs GH, Polovina JJ (2008) TurtleWatch: a tool to aid in the bycatch reduction of loggerhead turtles Caretta caretta in the Hawaii-based pelagic longline fishery. Endang Species Res 5:267-278

> Ilangakoon A, Sutaria D, Hines E, Raghavan R (2008) Community interviews on the status of the dugong (Dugong dugon) in the Gulf of Mannar (India and Sri Lanka). Mar Mamm Sci 24:704-710

> Jaramillo-Legorreta A, Rojas-Bracho L, Brownell RL Jr, Read AJ, Reeves RR, Ralls K, Taylor BL (2007) Saving the vaquita: immediate action, not more data. Conserv Biol 21:1653-1655

Kaczynski VM, Fluharty DL (2002) European policies in West Africa: who benefits from fisheries agreements? Mar Policy 26:75-93

> Karamanlidis AA, Androukaki E, Adamantopoulou S, Chatzispyrou A and others (2008) Assessing accidental entanglement as a threat to the Mediterranean monk seal Monachus monachus. Endang Species Res 5:205-213

Kelleher K (2005) Discards in the world's marine fisheries: An update. Food and Agriculture Organization of the United Nations, Fisheries and Aquaculture Department, Rome. Available at: ftp://ftp.fao.org/docrep/fao/008/ y5936e/y5936e00.pdf

Kerstetter DW, Graves JE (2006) Effects of circle versus Jstyle hooks on target and non-target species in a pelagic longline fishery. Fish Res 80:239-250

Kraus SD, Read AJ, Solow A, Baldwin K, Spradlin T, Anderson A, Williamson J (1997) Acoustic alarms reduce porpoise mortality. Nature 388:525

Levesque JC (2008) International fisheries agreement: Review of the International Commission for the Conservation of Atlantic Tunas case study - shark management. Mar Pol 32:528-533

Lewison RL, Crowder LB, Read AJ, Freeman SL (2004a) Understanding impacts of fisheries bycatch on marine megafauna. Trends Ecol Evol 19:598-604

> Lewison RL, Freeman SL, Crowder LB (2004b) Quantifying the effects of fisheries on threatened species: The impact of pelagic longlines on loggerhead and leatherback sea turtles. Ecol Lett 7:221-231

Lewison RL, Soykan CU, Franklin J (in press) Mapping the bycatch seascape: Multi-taxa and multi-scale spatial patterns of fisheries bycatch. Ecol Appl

Macys S, Wallace GN (2003) Marine turtle conservation on Holbox Island, Quintana Roo, Mexico: The fishermen's perceptions. Chelonian Conserv Biol 4:620-625

Middleton DAJ, Starr PJ, Gilbert DJ (2007) Modeling the impact of fisheries bycatch on Hector's dolphin: Comment on Slooten (2007). Endang Species Res 3:331-334

Moore JE, Read AJ (in press) A Bayesian uncertainty analysis of cetacean demography and bycatch mortality using ageat-death data. Ecol Appl

Moore JE, Wallace BP, Lewison RL, Zydelis R, Cox TM, Crowder LB (2008) A review of marine mammal, sea turtle and seabird bycatch in USA fisheries and the role of policy in shaping management. Mar Pol doi:10.1016/ j.marpol.2008.09.003 
Mug M, Hall MA, Vogel N (2008) Bycatch initiative: Eastern Pacific programme. A vehicle towards sustainable fisheries. Progress report of fishing experiments with modified gear (2004-2007), World Wildlife Fund and InterAmerican Tropical Tuna Commission

Nel DC, Ryan PG, Watkins BP (2002) Seabird mortality in the Patagonian toothfish longline fishery around the Prince Edward Islands, 1996-2000. Antarct Sci 14:151-161

Novacek MJ (2008) Engaging the public in biodiversity issues. Proc Natl Acad Sci USA 105(1):11571-11578

Peckham SH, Diaz DM, Walli A, Ruiz G, Crowder LB, Nichols WJ (2007) Small-scale fisheries bycatch jeapordizes endangered Pacific loggerhead turtles. PLoS One 2:e1041

Peckham SH, Maldonado-Diaz D, Koch V, Mancini A, Gaos A, Tinker MT, Nichols WJ (2008) High mortality of loggerhead turtles due to bycatch, human consumption and strandings at Baja California Sur, Mexico, 2003 to 2007. Endang Species Res 5:171-183

Perrin WF, Van Waerebeek K (2007) The small-cetacean fauna of the west coast of Africa and Macaronesia: diversity and distribution. In: Western African talks on cetaceans and their habitats, UNEP/CMS-WATCH-Inf.6, Convention on the conservation of migratory species of wild animals, Adeje, Tenerife. Available at: www.cms. int/species/waam/watch1_docs/Inf06_Small_Cetacean_ Fauna_E.pdf

Petersen SL, Phillips RA, Ryan PG, Underhill LG (2008) Albatross overlap with fisheries in the Benguela Upwelling System: implications for conservation and management. Endang Species Res 5:117-127

Prellezo R, Gallastegui MC (2008) Gear-selectivity-based regulation in a mixed fishery. Endang Species Res 5: 335-344

Salas S, Chuenpagdee R, Seijo J, Charles A (2007) Challenges in the assessment and management of small-scale fisheries in Latin America and the Caribbean. Fish Res 87: $5-16$

Scheidat M, Gilles A, Kock KH, Siebert U (2008) Harbour porpoise Phocoena phocoena abundance in the southwestern Baltic Sea. Endang Species Res 5:215-223

Slooten E (2007a) Conservation management in the face of uncertainty: effectiveness of four options for managing Hector's dolphin bycatch. Endang Species Res 3:169-179

Slooten E (2007b) Criticism is unfounded: reply to Middleton et al. (2007). Endang Species Res 3:335-339

Snover JL, Heppell SS (in press) Application of a diffusion approximation for risk assessments of sea turtle populations. Ecol Appl

Southwood A, Fritsches K, Brill R, Swimmer Y (2008) Sound, chemical, and light detection in sea turtles and pelagic fishes: sensory-based approaches to bycatch reduction in longline fisheries. Endang Species Res 5:225-238

Stevens JD, Bonfil R, Dulvy NK, Walker PA (2000) The effects of fishing on sharks, rays, and chimaeras (chondrichthyans), and the implications for marine ecosystems. ICES J Mar Sci 57:476-494
Sumaila UR, Alder J, Keith H (2006) Global scope and economics of illegal fishing. Mar Policy 30:696-703

Taylor BL, Wade PR, De Master DP, Barlow J (2000) Incorporating uncertainty into management models for marine mammals. Conserv Biol 14:1243-1252

Tomás J, Gozalbes P, Raga JA, Godley BJ (2008) Bycatch of loggerhead sea turtles: insights from 14 years of stranding data. Endang Species Res 5:161-169

Turner SJ, Thrush SF, Hewitt JE, Cummings VJ, Funnell G (1999) Fishing impacts and the degradation or loss of habitat structure. Fish Manag Ecol 6:401-420

> Véran S, Gimenez O, Flint E, Kendall WL, Doherty PF Jr, Lebreton JD (2007) Quantifying the impact of longline fisheries on adult survival in the black-footed albatross. J Appl Ecol 44:942-952

> Wade PR (1998) Calculating limits to the allowable humancaused mortality of cetaceans and pinnipeds. Mar Mamm Sci 14:1-37

Wallace BW, Heppell SS, Lewison RL, Kelez S, Crowder LB (2008) Reproductive values of loggerhead turtles in fisheries bycatch worldwide. J Appl Ecol 45: 1076-1085

Watkins BP, Petersen SL, Ryan PG (2008) Interactions between seabirds and deep water hake trawl gear: an assessment of impacts in South African waters. Anim Conserv 11(4):247-254

Watson R, Pauly D (2001) Systematic distortion in world fisheries catch trends. Nature 414:534-536

Watson JW, Epperly SP, Shah AK, Foster DG (2005) Fishing methods to reduce sea turtle mortality associated with pelagic longlines. Can J Fish Aquat Sci 62: 965-981

Weimerskirch H, Catard A, Prince P, Cherel Y, Croxall J (1999) Foraging white-chinned petrels Procellaria aequinoctialis at risk: from the tropics to Antarctica. Biol Conserv 87:273-275

Werner T, Krauss K, Read A, Zollett E (2006) Fishing techniques to reduce the bycatch of threatened marine animals. Mar Technol Soc J 40:77-95

Wilcox C, Donlan CJ (2007) Compensatory mitigation as a solution to fisheries bycatch-biodiversity conservation conflicts. Front Ecol Environ 5:325-331

Xue G (2006) China's distant water fisheries and its response to flag state responsibilities. Mar Policy 30:651-658

Young JL, Bornik ZB, Marcotte ML, Charlie KN, Wagner GN, Hinch SG, Cooke SJ (2006) Integrating physiology and life history to improve fisheries management and conservation. Fish Fish 7:262-283

Zador SG, Punt AE, Parrish JK (2008a) Population impacts of endangered short-tailed albatross bycatch in the Alaskan trawl fishery. Biol Conserv 141:872-882

Zador SG, Parrish JK, Punt AE, Burke JL, Fitzgerald SM (2008b) Determining spatial and temporal overlap of an endangered seabird with a large commercial trawl fishery. Endang Species Res 5:103-115

Žydelis R, Dagys M, Vaitkus G (2006) Beached bird surveys in Lithuania reflect marine oil pollution and bird mortality in fishing nets. Mar Ornithol 34:161-166 